\title{
Protective effects of leptin against cerebral ischemia/reperfusion injury (Review)
}

\author{
WEN-FANG ZHANG ${ }^{1}$, YIN-CHUAN JIN ${ }^{2}$, XIAO-MEI LI ${ }^{3}$, ZHI YANG $^{3}$, DONG WANG ${ }^{3}$ and JING-JING CUI $^{4}$ \\ ${ }^{1}$ Department of Biomedical Research Center; ${ }^{2}$ Department of Histology and Embryology, \\ Binzhou Medical University; ${ }^{3}$ Department of Cardiology, Yantai Affiliated Hospital of Binzhou Medical University,

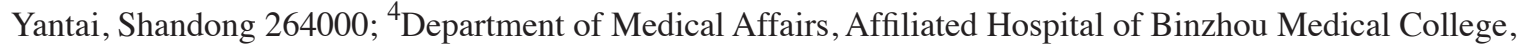 \\ Binzhou, Shandong 256603, P.R. China
}

Received April 13, 2018; Accepted February 4, 2019

DOI: $10.3892 /$ etm.2019.7377

\begin{abstract}
In recent years, the use of thrombolytic therapy for treating ischemia/reperfusion injury has resulted in damage to the self-regulatory mechanisms of the brain. This is due to the increased production of free radicals, excitatory amino acids and pro-inflammatory cytokines causing secondary damage to the brain. Simple thrombolytic therapy has not been the best approach for treating ischemia/reperfusion injury. Excessive perfusion leads to failure of the body's self-regulatory functions, which in turn increases the area of cerebral edema and aggravates cerebral ischemia. Previous studies have evaluated the satiety hormone leptin as a link between energy expenditure and obesity. Of note, leptin, which is involved in brain development, synaptic transmission and angiogenesis following ischemia/reperfusion injury, has been considered an important factor for treating ischemia/reperfusion injury. The present review outlines the discovery of leptin and discusses its association with cerebral ischemia/reperfusion.
\end{abstract}

\section{Contents}

1. Introduction

2. Production and metabolism of leptin

3. Leptin receptors

4. Leptin signaling pathway

5. Roles of leptin

Correspondence to: Professor Jing-Jing Cui, Department of Medical Affairs, Affiliated Hospital of Binzhou Medical College, 661 2nd Yellow River Road, Binzhou, Shandong 256603, P.R. China E-mail: byfyproc@126.com

Professor Dong Wang, Department of Cardiology, Yantai Affiliated Hospital of Binzhou Medical University, 717 Jinbu Street, Muping, Yantai, Shandong 264000, P.R. China

E-mail: binyiwangdong@126.com

Key words: leptin, excitatory amino acid, free radicals, mitochondria, brain
6. Protective mechanisms of leptin in the brain

7. Conclusion and outlook

\section{Introduction}

Stroke is a partial or complete brain dysfunction syndrome accompanied by acute cerebral circulatory disorders (1). Stroke globally affects millions of individuals each year (2). Of note, its incidence rate exceeds that of heart disease. In particular, stroke has major life-long consequences. Ischemic stroke, accounting for $70-80 \%$ of all strokes, is caused by disturbances in cerebral circulation, leading to cerebral ischemia, hypoxia, neuronal apoptosis and necrosis, thereby leading to dysfunctions. Reconstruction or enhancement of blood flow in the ischemic region is the current key treatment strategy for stroke-associated ischemic brain injury. Recent developments in thrombolytic therapy have led to increases in free radical production, with consequent damage to the self-regulation mechanisms of brain tissues (3). The latter may determine secondary damage to cerebral vessels following cerebral ischemia/reperfusion. Of note, excessive perfusion may lead to the failure of the self-regulation mechanisms of brain tissues, thereby increasing the area of brain edema and aggravating cerebral ischemia. At present, ischemia/reperfusion injury is receiving an increased amount of attention; however, neuroprotective drugs currently used for treating neuronal injury caused by cerebral ischemia/reperfusion are unable to repair and perfuse injured neurons $(4,5)$. Of note, clinicians are currently unable to obtain good results owing to the time constraints associated with and several side effects of thrombolytic and traditional medical therapies. The development of a novel drug capable of dealing with the multiple mechanisms involved in ischemia/reperfusion injury is warranted (6). In recent years, leptin has been linked to the occurrence and development of cerebrovascular diseases. The metabolism and mechanism of action of leptin is similar in animals and humans; however, the effective dose of leptin used in animals is not feasible for use in humans due to drug pharmacokinetics $(7,8)$. Leptin receptor binding reportedly regulates energy metabolism, respiration, neuroendocrine function, immune inflammation, and afferent nerve and neuron regeneration. An obesity-associated gene 
encoding leptin (OB-Rs), to which leptin binds, are widely distributed in humans and rodents. In particular, OB-Rs are distributed in the arcuate nucleus of the hypothalamus and the lateral hypothalamus as well as in the ventromedial, paraventricular, supraoptic and ventral perimammary nuclei (9). Of note, leptin receptors were determined to be distributed in the cortex, hippocampus and striatum in a murine model of ischemia/reperfusion with leptin pre-conditioning (Fig 1) $(10,11)$. Leptin receptors in locations including the striatum have protective roles (12). Studies have demonstrated considerable reductions in excitatory amino acids (EAAs) $(13,14)$, oxygen free radicals, inflammatory factors (15-17), mitochondrial damage and apoptosis in leptin-preconditioned groups compared with those in untreated groups (Fig. 2). Leptin has an important role in decreasing excitatory neurotransmitter levels, protecting the mitochondria, decreasing superoxide and free radical formation, increasing anti-inflammatory factor and -apoptotic protein levels, decreasing apoptotic protein levels, and avoiding the traditional role of protecting the brain from single and potential side effects. In the present review, the protective mechanisms of leptin on the brain are summarized.

\section{Production and metabolism of leptin}

The leptin gene (OB gene) was originally produced by two mutant mouse strains (ob/ob and db/db; leptin-deficient and leptin-receptor-deficient, respectively) developed by the Jackson Laboratory (Bar Harbor, ME, USA). These diabetic mice (db mice) had obesity, polyphagia and polyuria as comorbidities (18). Obese mice (ob mice) encode an appetite suppressor present in the blood, which was dectected by conjoined symbiotic experiments. db mice lack the corresponding receptor was discovered by conjoined symbiosis experiments (19). In 1994, Zhang et al (20) located the human OB gene encoding the peptide hormone leptin to chromosome 7 (7q31.3) via positional cloning. Subsequently, in 1995 , Halaas et al (21) reported on the synthesis of the leptin protein. The metabolism of leptin may be summarized as follows (22): Leptin is a $16-\mathrm{kDa}$ non-glycosylated protein encoded by the OB gene, which is located on the human chromosome 7 and the mouse chromosome 6 . The precursor of leptin is a protein with 167 amino acids. During its secretion into the blood, the signal peptide, composed of 21 hydrophilic amino acid residues at the amino end, is hydrolyzed to form a polypeptide chain composed of 146 amino acids (Fig. 1A). It is primarily synthesized by the white adipose tissue, and leptin transport in the brain is identical in humans and mice. Due to its large size, leptin cannot passively cross the blood-brain barrier (BBB). Therefore, it is transported across via a regulated saturable transport system $(23,24)$. Although the molecular identity of this transporter system remains elusive, it appears to act independently from leptin receptors. Studies $(8,25,26)$ have reported three mechanisms that aid the transport of leptin across the BBB: Unidirectional Saturable (Leptin transport to cerebrospinal fluid is saturated but not unlimited) transport of leptin across the BBB; direct access of the leptin receptor neurons to the circulation via projections close to fenestrated capillaries (perivascular space) in circumventricular organs (e.g., median eminence, area postrema and organum vasculum); and transport of leptin by tanycytes into the cerebrospinal fluid within the ventricular space. Leptin has strong hydrophilicity and is mostly excreted by the kidneys. These mechanisms serve as the basis for the administration of leptin through the lateral ventricle to enhance its neuroprotective effects.

\section{Leptin receptors}

Leptin receptors (OB-Rs) are expressed in several organs and tissue types, including the hypothalamus, pituitary gland, lymph nodes, liver, lungs, uterus, adipose tissues, kidneys, pancreas, stomach and gonads. Astrocytes are known to express various isoforms of the leptin receptor (18-20). OB-R splicing produces six isomers of the leptin receptor, named as OB-Ra-f (Fig. 1B). Of those six, OB-Rb is the longest receptor, and OB-Ra and $\mathrm{OB}-\mathrm{Rc}$ are widely distributed and are predominant in the brain's choroid plexus and microvasculature. The distribution of leptin receptors is central to the regulation of leptin transport, protein binding and the free leptin in the blood through the BBB. The distribution of leptin receptors regulate the amount of leptin passing through the BBB (27). OB-Re exclusively contains extracellular domains, circulating as a soluble receptor. By contrast, other OB-Rs have identical N-terminals as well as intracellular membranes and extracellular domains. OB-Rd and OB-Rf, which are types of single transmembrane receptors, only have partial functions. Among other OB-Rs, they are widely expressed in the testicles, brain, liver, heart and lung tissues. OB-Rb (Fig. 3), a leukocyte type-6 receptor encompassing an intracellular region, is considered the only functional receptor involved in cellular signal transduction (comprising intracellular, membrane and extracellular regions). The extracellular region is a single transmembrane signal transduction protein comprising two cytokines, combining the characteristic sequences (cytokine receptor homology domains separated by an immunoglobulin-like domain) and a fibronectin III region. The membrane and intracellular regions are characterized by the same 29 amino acids of a highly conserved Box1 motif rich in proline, two conservative Box 2 motifs and three conservative tyrosine residues (Tyr985, Tyr1077 and Tyr1138) (28). Similarly, $\mathrm{OB}-\mathrm{Rb}$ expresses various isoforms of the leptin receptor and is prevalent in numerous areas of the mammalian brain, including the cortex, hippocampus and striatum within neurons and astrocytes, and in Schwann cells (29). Leptin receptors undergo mutagenesis in the hypothalamus, hippocampus and prefrontal cortex of $\mathrm{db} / \mathrm{db}$ mice. Such an occurrence may be responsible for the decreased neuroprotective functions of leptin following ischemia/reperfusion injury. While leptin receptors do not possess intrinsic enzyme activity, they may bind to tyrosine kinase in the cytoplasm. Furthermore, $(19,30)$ in the brain, exogenous leptin combined with the $\mathrm{OB}-\mathrm{Rb}$ has protective roles in the BBB. However, the functions of short-form leptin receptors remain to be fully elucidated.

\section{Leptin signaling pathway}

The binding of leptin to its receptors, OB-Rs, in the central and peripheral tissues results in a wide range of biological effects (31). The signal transduction pathways are mediated at the membrane surface by long functional receptors, $\mathrm{OB}-\mathrm{Rb}$ (Figs.1 and3); theseincludeJanuskinase(JAK)/signaltransducer and activator of transcription (STAT) (32), Ras/extracellular 

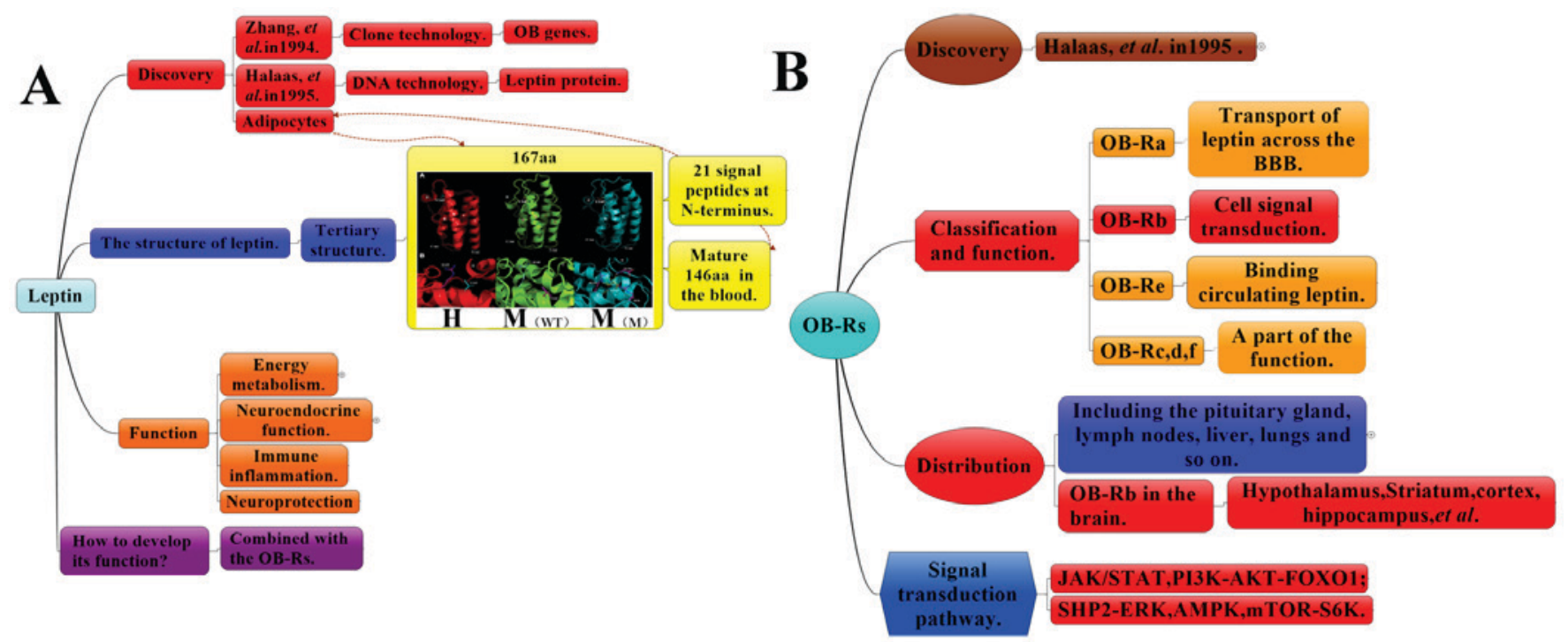

Figure 1. (A) Summary of the discovery, construction and function of leptin. Leptin is composed of 167 amino acids. Of these, 21 amino acids are released from the $\mathrm{N}$-terminus in the mature leptin occurring in the blood. The tertiary structure of leptin is adapted from the National Centre for Biotechnology Information GenBank database; red indicates humans, green indicates wild-type mice and blue indicates mutant mice. (B) Summary of the discovery, construction and function of leptin receptors. BBB, blood-brain barrier; CNS, central nervous system; OB-Rs, leptin receptor; JAK2, tyrosine kinase Janus kinase 2; STAT3, signal transducer and activator of transcription 3; PI3K phosphatidylinositide-3 kinase; AMPK, adenosine monophosphate kinase; mTOR, mammalian target of rapamycin; S6K, ribosomal protein S6 kinase B1; FoxO1, forkhead box protein O1; SHP2, SH2 domain of protein tyrosine phosphatase 2; ERK, extracellular signal-regulated kinase; MAPK, mitogen-activated protein kinase. H, human; M, mouse; WT, wild type; M, mutant.

signal-regulated kinase (ERK)1/2 (33), phosphoinositide-3 kinase (PI3K)/Akt/forkhead box O1 (34), SH2 domain of protein tyrosine phosphatase 2/ERK, adenosine monophosphate kinase (AMPK) and mammalian target of rapamycin/ ribosomal protein S6 kinase B1 $(11,35)$. JAK/STAT is the most important signaling pathway and has a major role in cerebral protection (36). Suppressor of cytokine signaling reportedly inhibits the JAK/STAT signaling pathway $(37,38)$ Phosphorylation of tyrosine residues (Tyr1138) was triggered and JAK2 was activated by OB-R, thereby combining $\mathrm{OB}-\mathrm{Rb}$ in cells; the phosphorylated site of $\mathrm{OB}-\mathrm{Rb}$ serves as a docking site and recruits the STAT3 monomer (39). STATs are a group of cytoplasmic proteins that act as signal transducers and transcription factors and participate in normal cell - cytokine interaction and cell growth (40). STAT3, a potential transcription factor belonging to the STAT family, reaches the receptor and binds to the $705^{\text {th }}$ tyrosine site via phosphorylation. In particular, STAT3 is phosphorylated by phosphorylated (p)-JAK2 $(41,42)$. p-STAT3 behaves homotypic or heterodimeric, depending on the action of the $\mathrm{SH} 2$ region, and is then transferred to the cell nucleus. p-STAT3 regulates downstream target genes by interacting with DNA elements, other transcription factors or adjunct proteins. The neuroprotective mechanism of leptin and the JAK2/STAT3 signal transduction pathway are closely associated.

\section{Roles of leptin}

Studies have reported on the pleiotropic effects of leptin on various biological functions of the central and peripheral nervous systems. The presence of leptin receptors in various tissues suggests its pleiotropic effects on numerous biological functions (43-45). Certain arcuate nucleus (ARC) leptin receptor (OB-Rs) neurons express pro-opiomelanocortin
(POMC). Other ARC OB-Rs neurons express agouti-related protein (AGRP) along with the inhibitory neuropeptide $\mathrm{Y}$ (NPY) and the inhibitory neurotransmitter $\gamma$-aminobutyric acid (GABA). POMC-expressing neurons have low energy requirements, thereby promoting energy expenditure, whereas those expressing AGRP, NPY and GABA demonstrate opposite behaviors $(32,33)$. Blood leptin levels are typically proportional to body fat levels. In particular, they reflect the organism's energy storage, with no effects on obesity, thereby revealing the pathological state of leptin resistance (46). Body weight and the hypothalamus-pituitary-gonad axis, which is closely associated with growth and weight, may be regulated by leptin. The levels of circulating leptin predict the development of heart failure in elderly individuals by modulating the influence of obesity on the increasing risk of heart failure. Indeed, the influence of leptin on the central nervous system (CNS) increases the sympathetic activity of the nerves sub-serving various tissues, including the cardiovascular organs and kidneys (33). In mice, blocking PI3K with either LY294002 or wortmannin significantly attenuated the leptin-induced increase in renal sympathetic activity. Of note, leptin promotes the switch toward type $1 \mathrm{~T}$-helper (Th1) cell immune responses by increasing interferon- $\gamma$ secretion, facilitating Th17 responses (47), and stimulating the release of inflammatory cytokines, including interleukin (IL)-1beta, IL-6 and IL-8, and the chemokine monocyte chemotactic protein-1.

Although most animal studies have indicated that leptin protects the brain, human studies suggest certain contradictions. What is known for certain is that the increased circulating leptin levels may also contribute to low brain natriuretic peptide concentrations observed in heart failure patients with a high body mass index and may promote the obesity paradox of heart failure (48). In particular, the administration of leptin $(14.1 \mathrm{ng} / \mathrm{ml})$ to humans would establish a risk model in coronary 


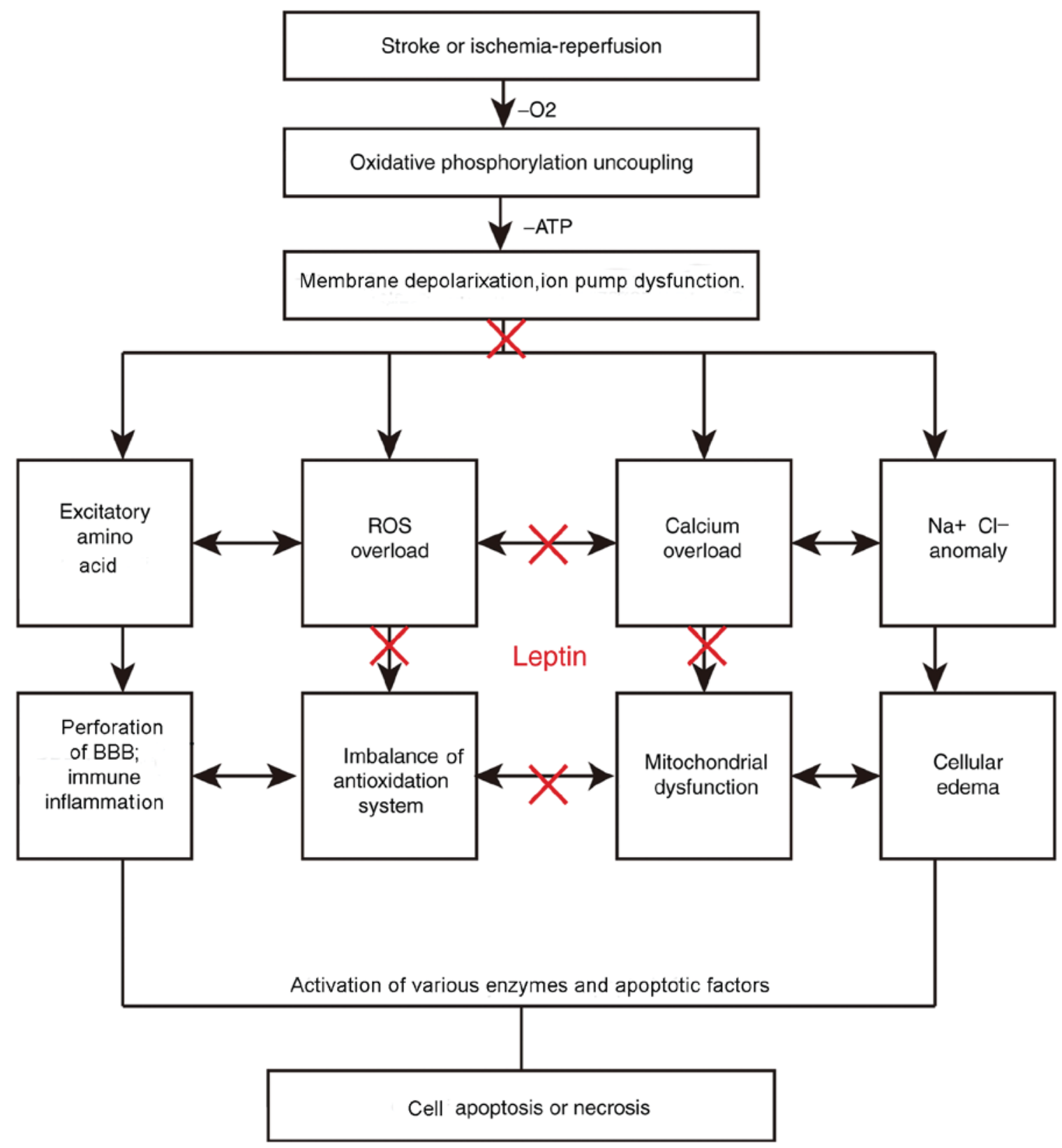

Figure 2. Mechanism of cerebral ischemia. Stroke or ischemia/reperfusion injury leads to ischemia and hypoxia and reduced energy production in brain tissue. The membrane potential and ion pump are destroyed. In the cells, numerous enzymes and apoptotic factors are activated. Subsequently, following a chain reaction, brain cells die. Leptin may cause a reduction of excitatory amino acid and ROS production by balancing the difference of ion concentration inside and outside the membrane to improve mitochondrial function. BBB, blood-brain barrier; ROS, reactive oxygen species.

artery disease. Furthermore, a prospective study involving 4,571 healthy African Americans did not identify any association between the leptin levels in the body and the risk of ischemic stroke in either men or women (49-51). A few small-scale studies evaluated leptin levels in the body during the acute phase of ischemic stroke and reported an increase in the levels (52). The patients received escalating doses of r-met-Hu-Leptin until a dose of $0.12 \mathrm{mg} / \mathrm{kg} /$ day was reached. After 18 months of r-Met-Hu-Leptin therapy, a considerable improvement in glucose homeostasis was achieved, as evidenced by the normalization of fasting blood glucose levels, lowered glycated hemoglobin and improved tolerance to an oral glucose load $(7,52,53)$. In recent years, significant efforts have been made to clarify the neuroprotective mechanisms of leptin.

\section{Protective mechanisms of leptin in the brain}

The pathogenesis of cerebral ischemia/reperfusion injury has been linked to increases in the toxicity of EAAs (54), mitochondrial damage (55), free oxygen radical production, inflammatory factors and apoptosis, as well as the interaction among those factors (Fig. 2). EAAs, including glutamic and aspartic acids, are present in the mammalian CNS and most abundantly in the cerebral cortex and hippocampus, where they deliver excitatory nerve impulses (56). N-Methyl-D-aspartic acid receptors are expressed in oligodendrocytes. Of note, $40 \%$ of glutamic acid is released from synapses that are activated during ischemia (57). In general, EAAs present in the synaptic vesicles of nerve endings are released into the synaptic cleft 


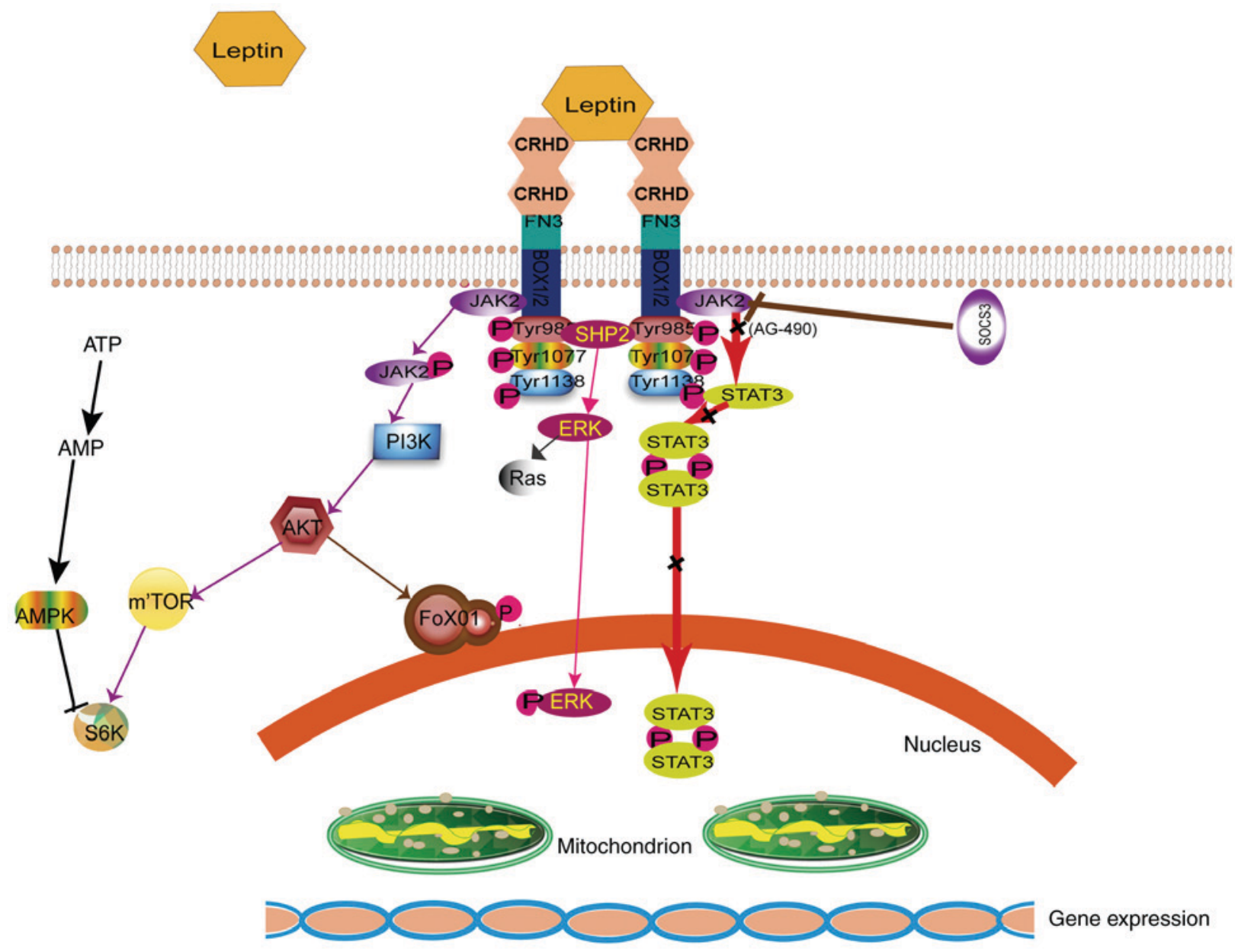

Figure 3. Leptin signaling pathways. Leptin binds with OB-Rb and activates JAK2 in box1/2 (cytoplasmic motif located in the membrane proximal region of cytokine receptors). JAK2 is phosphorylated at 3 tyrosine residues. Subsequently, downstream pathways, including JAK2/STAT3, PI3K/AKT/mTOR/S6K, AKT/FOXO1 and SHP2/ERK or Ras are activated. AMP is able to activate AMPK. Leptin has an important role in brain protection. Specifically, it activates the JAK2/STAT3 signaling pathway. However, AG-490 is capable of reversing this brain-protective effect. Finally, SOCS3 negatively regulates OB-Rb signaling. JAK2, tyrosine kinase Janus kinase 2; CRHD, cytokine receptor homology domain; FN3, membrane proximal fibronectin type III; bs; STAT3, signal transducer and activator of transcription 3; PI3K, phosphatidylinositide-3 kinase; AMP, adenosine monophosphate; mTOR, mammalian target of rapamycin; S6K, ribosomal protein S6 kinase B1; FoxO1, forkhead box protein O1; SH2, Src homology 2 domain; SHP2, SH2 domain of protein tyrosine phosphatase 2; ERK, extracellular signal-regulated kinase; MAPK, mitogen-activated protein kinase; AG-490, Janus kinase/signal transduction protein and transcriptional inhibitor activator; SOCS3, suppressor of cytokine signaling 3; P, phosphate; OB-Rs, leptin receptor.

acting on the corresponding receptor, transmitting nerve impulses once the nerve cell membrane is depolarized. Excessive excitatory transmitters are either hydrolyzed by proteases or re-absorbed by neurons (57). Calcium, sodium and potassium channels are activated following cerebral ischemia. Excitatory neurotransmitters are simultaneously released in the synaptic space and cannot be absorbed or used effectively. The accumulation of sodium and chloride ions causes cellular edema, thereby resulting in the accumulation of excitatory amino acids in interstitial cells, causing cellular toxicity. Dopaminergic neurons of the striatum and prefrontal cortex originate from the ventral tegmental area (VTA) of the mesencephalon.

Leptin treatment provided following transient ischemia markedly reduces neurologic deficits, cerebral infarct volumes and brain edema $(58,59)$. Leptin treatment increased the ATP, leptin and p-Akt levels and decreased the lactate dehydrogenase levels and lactic acid/pyruvate ratio; it also alleviated histopathologic injuries, all of which were entirely reversed following treatment with the PI3K inhibitor LY294002.
Leptin inhibits the release of pre-synaptic glutamate into the VTA via JAK2 and PI3K activation. Furthermore, leptin reportedly suppresses the release of glutamate and regulates the dopamine pathway in the hippocampus to alleviate the depressive symptoms of cerebral ischemia. AG-490, a JAK2 signal transduction protein and transcriptional inhibitor activator, inhibits the effects of leptin on JAK2/PI3K signaling. $(60,61)$ The JAK2/PI3K/Akt pathway is critical for the mediation of leptin-induced neuroprotection. These results support the use of leptin in the treatment of ischemic stroke. The effects of leptin in increasing angiogenesis and neurogenesis following brain ischemia may be partially attributed to an increase in OB-Rs, AMPK activation, transient receptor potential cation channel subfamily $\mathrm{V}$ member 1 expression and biosynthesis of pro-angiogenic factors (e.g., vascular endothelial growth factor). By contrast, studies assessing microsphere infusion under maximal vasodilation have reported that that leptin does not have a central role in cerebral perfusion enhancement $(59,62)$. Systemic leptin administration for 1 week following an occlusion 
surgery increased the cerebral hemodynamic reserve in a similar fashion to that caused by granulocyte-macrophage colony-stimulating factor. Leptin enhances cell growth and differentiation via the mitogen-activated protein kinase/ERK signaling pathway. Leptin infusion increases Akt and ERK1/2 phosphorylation in brain tissues. These effects were associated with upregulation of ERK1/2 phosphorylation and nitric oxide (NO) release, which promote the repair of damaged mucosa $(63,64)$. Mitochondria are the powerhouse of cells. Ischemic or hypoxic injury to the brain terminates mitochondrial oxidative phosphorylation (65), thereby leading to the loss of mitochondrial membrane potential and decreasing the membrane permeability of ATP $(66,67)$. Ischemia/reperfusion leads to further mitochondrial damage; in particular, it causes secondary damage with the release of cellular oxygen free radicals due to a series of chain reactions involving cell membrane damage, lysosome rupture and cell lysis. Mitochondrial biogenesis is promoted via the activation of JAK/STAT by leptin, via downstream proteins, such as proliferator-activated receptor $\gamma$ a co-activator- $1 \alpha$ and mitochondrial transcription factor A. Such activation has been indicated to be involved in neuronal cell protection via the enhancement of anti-oxidant enzyme activities $(15,47)$. It has been demonstrated that leptin increases superoxide dismutase (SOD) levels, stabilizes the mitochondrial membrane and alleviates endoplasmic reticulum pressure (17); this in turn inhibits the production of free radicals and ischemic injury in mice by binding to OB-Rb in the cortex, hippocampus and striatum. Inflammatory responses of leukocyte infiltration have an important role in cerebral ischemia and reperfusion. The reduction in oxidative damage to brain tissue caused by reactive oxygen represents a therapeutic approach for cerebral ischemia/reperfusion injury (1). Oxygen free radicals activate inflammatory cytokines and amplify inflammatory signals $(68,69)$. Upregulation of adhesion molecule expression on the surface of neutrophils, reactive leukocytes and vascular endothelial cells was observed; furthermore, there was an increase in neutrophil adhesion to vascular endothelial cells $(70,71)$.

In cerebral ischemia/reperfusion injury, inflammation caused by leukocyte infiltration and fluid has an important role; a therapeutic target is represented by oxidative damage of the brain tissue determined by reactive oxygen species (ROS) (72). In particular, the latter activates inflammatory cytokines and amplifies inflammatory signals $(71,73)$. Hence, upregulation of adhesion molecule expression on the neutrophil surface, reactive leukocytes and vascular endothelial cells may be observed. In addition, neutrophil adhesion to vascular endothelial cells inhibited the production of NO, as determined by the aggravation of cell edema (74). Leptin has an anti-inflammatory role $(75,76)$; it activates the nuclear factor- $\kappa \mathrm{B}$ pathway, inhibits the expression of pro-inflammatory factors [tumor necrosis factor (TNF)- $\alpha$, IL-6, IL-1 $\beta$ ] within $7 \mathrm{~h}$ and increases the expression of IL-10 $(74,77)$ Within 100 min, the human body is able to recover from hypothermia and hypotension caused by ischemia/reperfusion injury (78). Within 90-240 $\mathrm{min}, \mathrm{TNF}-\alpha$ is inhibited. This is not accompanied by changes in the levels of other cytokines. In 1981, the concept of ischemic penumbra, which refers to the reversible damage caused by the brain outside the central area of focal ischemic necrosis, was introduced (79). While the energy supply ceases, the ionic pump in the cell remains accessible. The ischemic penumbra, an area unaffected by the stroke for a few hours from its occurrence, represents an important therapeutic target $(3,80)$. During cerebral ischemia/reperfusion, oxidative stress leads to the breakdown of the redox balance; this is due to the accumulation of ROS and the dysfunction of important redox-sensitive protein kinases, membrane receptors and ion channels (81). ROS may damage DNA to trigger apoptosis, peroxidising the phospholipid membrane and releasing cytochrome $\mathrm{C}$ from the mitochondria, thereby leading to activation of pro-apoptotic caspases and apoptosis initiation (13). Leptin treatment causes the production of SOD, upregulation of the anti-apoptotic protein B-cell lymphoma-2 (Bcl-2) and downregulation of caspase-3 and $\mathrm{Bcl}-2$-associated $\mathrm{X}$ protein expression. This stabilizes the mitochondrial membrane potential, and reduces oxidative stress and induction of apoptosis (82).

\section{Conclusion and outlook}

Stroke determines high morbidity, disability and mortality following cancer, and precedes cardiovascular disease (83). Leptin has an important role in decreasing excitatory neurotransmitter levels, protecting mitochondria, decreasing superoxide and free radical formation, increasing anti-inflammatory factor and -apoptotic protein levels, decreasing apoptotic protein levels and avoiding thrombolysis and the risk of cerebral hemorrhage (84). Leptin has drawn the attention of numerous experts and scholars. Several studies have indicated that exogenous leptin has a protective role in the brain (85), while also interfering with the body's energy regulation. Most studies on human subjects are relevant and provide contradictory points of view regarding leptin in this field. Regarding the association of the serum levels of leptin with stroke, the opinion of scholars is divided. By contrast, a prospective study on 4,571 healthy African Americans did not identify any association between leptin levels and ischemic stroke risk in either men or women $(8,22,51,86)$. Only a few small studies evaluated leptin levels during the acute phase of ischemic stroke and reported increased leptin levels $(7,26,50,52,87)$. It is currently indicated that leptin administration after stroke may be a promising treatment strategy. In particular with use of a gel, the polymer (synthetic leptin protein) may be directed to the damaged brain tissue to stimulate different functions, including the regulation of nutrition and growth, and the differentiation of neural stem cells. Based on these results, leptin may be selectively administered to the damaged parts of the brain to subsequently observe whether leptin stimulates the growth and differentiation of neural stem cells (88-90). However, further research is warranted in this regard. Leptin is a novel brain protective drug, but its application has not yet been successfully translated into the clinic. Additional research is required to implement applications developed in animal experiments as clinical treatments in humans.

\section{Acknowledgements}

Not applicable. 


\section{Funding}

This study was supported by the Shandong Provincial Natural Science Foundation, China (grant no. ZR2014HM026), the National Natural Science Foundation of China (grant no. 81701301) and the Science and Technology Plan of Universities in Shandong Province (grant no. J14LL01).

\section{Availability of data and materials}

Not applicable.

\section{Authors' contributions}

WZ, JC and DW conceived and designed the article. WZ and YJ analyzed the relevant literature. WZ wrote the manuscript and drew the figures. YJ, ZY, DW and XL made suggestions for revision. WZ, DW and JC are responsible for text layout.

\section{Ethics approval and consent to participate}

Not applicable.

\section{Patient consent for publication}

Not applicable.

\section{Competing interests}

The authors declare that they have no competing interests.

\section{References}

1. Chouchani ET, Pell VR, Gaude E, Aksentijević D, Sundier SY, Robb EL, Logan A, Nadtochiy SM, Ord ENJ, Smith AC, et al: Ischaemic accumulation of succinate controls reperfusion injury through mitochondrial ROS. Nature 515: 431-435, 2014.

2. Wu H, Tang C, Tai LW, Yao W, Guo P, Hong J, Yang X, Li X, Jin Z, Ke J and Wang Y: Flurbiprofen axetil attenuates cerebral ischemia reperfusion injury by reducing inflammation in a rat model of transient global cerebral ischemia reperfusion. Biosci Rep 38: BSR20171562, 2018.

3. Zhou H, Wang J, Jiang J, Stavrovskaya IG, Li M, Li W, Wu Q, Zhang X, Luo C, Zhou S, et al: N-acetyl-serotonin offers neuroprotection through inhibiting mitochondrial death pathways and autophagic activation in experimental models of ischemic injury. J Neurosci 34: 2967-2978, 2014.

4. Coutinho JM, Liebeskind DS, Slater LA, Nogueira RG, Clark W, Dávalos A, Bonafé A, Jahan R, Fischer U,Gralla J, et al: Combined intravenous thrombolysis and thrombectomy vs thrombectomy alone for acute ischemic stroke: A pooled analysis of the SWIFT and STAR studies. JAMA Neurol 74: 268-274, 2017.

5. El-Ghanem M, Al-Mufti F, Thulasi V, Singh IP and Gandhi C: Expanding the treatment window for ischemic stroke through the application of novel system-based technology. Neurosurg Focus 42: E7, 2017.

6. Oh HK, Choi YS, Yang YI, Kim JH,Leung PC and Choi JH: Leptin receptor is induced in endometriosis and leptin stimulates the growth of endometriotic epithelial cells through the JAK2/STAT3 and ERK pathways. Mol Hum Reprod 19: 160-168, 2013.

7. Gairolla J, Kler R, Modi M and Khurana D: Leptin and adiponectin: pathophysiological role and possible therapeutic target of inflammation in ischemic stroke. Rev Neurosci 28: 295-306, 2017.

8. Nowzari Z, Masoumi M, Nazari-Robati M, Akbari H, Shahrokhi N and Asadikaram G: Association of polymorphisms of leptin, leptin receptor and apelin receptor genes with susceptibility to coronary artery disease and hypertension. Life Sci 207: $166-171,2018$.
9. Deng ZH, Liao J, Zhang JY, Liang C, Song CH, Han M, Wang LH, Xue H, Zhang K, Zabeau L, et al: Inhibition of the connexin 43 elevation may be involved in the neuroprotective activity of leptin against brain ischemic injury. Cell Mol Neurobiol 34: 871-879, 2014.

10. Porzionato A, Rucinski M, Macchi V, Stecco C, Castagliuolo I, Malendowicz LK and De Caro R: Expression of leptin and leptin receptor isoforms in the rat and human carotid body. Brain Res 1385: 56-67, 2011.

11. Zhou Y and Rui L: Leptin signaling and leptin resistance. Front Med 7: 207-222, 2013.

12. Zhang JY, Yan GT, Liao J, Deng ZH, Xue H, Wang LH and Zhang K: Leptin attenuates cerebral ischemia/reperfusion injury partially by CGRP expression. Eur J Pharmacol 671: 61-69, 2011.

13. Zhang JY Jr, Si YL, Liao J, Yan GT, Deng ZH, Xue H, Wang LH and Zhang K: Leptin administration alleviates ischemic brain injury in mice by reducing oxidative stress and subsequent neuronal apoptosis. J Trauma Acute Care Surg 72: 982-991, 2012.

14. Tsuda K: Leptin and nitric oxide production against ischemic neuronal injury. Stroke 39: e3-e4, 2008.

15. Musman J, Pons S, Barau C, Caccia C, Leoni V, Berdeaux A, Ghaleh B and Morin D: Regular treadmill exercise inhibits mitochondrial accumulation of cholesterol and oxysterols during myocardial ischemia-reperfusion in wild-type and ob/ob mice. Free Radic Biol Med 101: 317-324, 2016.

16. Grabacka MM, Wilk A, Antonczyk A, Banks P, Walczyk-Tytko E, Dean M, Pierzchalska M and Reiss K: Fenofibrate induces ketone body production in melanoma and glioblastoma cells. Front Endocrinol (Lausanne) 7: 5, 2016.

17. Ye R, Yang Q, Kong X, Li N, Zhang Y, Han J, Xiong L, Liu X and Zhao G: Sevoflurane preconditioning improves mitochondrial function and long-term neurologic sequelae after transient cerebral ischemia: Role of mitochondrial permeability transition. Crit Care Med 40: 2685-2693, 2012.

18. Schwartz MW and Baskin DG: Leptin and the brain: then and now. J Clin Investig 123: 2344-2345, 2013.

19. Maffei M, Fei H, Lee GH, Dani C, Leroy P, Zhang Y, Proenca R, Negrel R, Ailhaud G and Friedman JM: Increased expression in adipocytes of ob RNA in mice with lesions of the hypothalamus and with mutations at the db locus. Proc Natl Acad Sci USA 92: 6957-6960, 1995.

20. Zhang Y, Proenca R, Maffei M, Barone M, Leopold L and Friedman JM: Positional cloning of the mouse obese gene and its human homologue. Nature 372: 425-432, 1994.

21. Halaas JL, Gajiwala KS, Maffei M, Cohen SL, Chait BT, Rabinowitz D, Lallone RL, Burley SK and Friedman JM: Weight reducing effects of the plasma protein Encoded by the obese gene. Science 269: 543-546, 1995.

22. Niklowitz P, Rothermel J, Lass N, Barth A and Reinehr T: Bioactive leptin is stronger related to parameters of fat mass and distribution than conventionally measured leptin: Findings from a longitudinal study in obese children participating in a lifestyle intervention. Clin Chim Acta 480: 225-229, 2018.

23. Munzberg $\mathrm{H}$ and Morrison CD: Structure, production and signaling of leptin. Metabolism 64: 13-23, 2015.

24. Perez-Perez A, Vilarino-Garcia T, Fernandez-Riejos P, Martin-Gonzalez J, Segura-Egea JJ and Sanchez-Margalet V: Role of leptin as a link between metabolism and the immune system. Cytokine Growth Factor Rev 35: 71-84, 2017.

25. Kastin AJ, Pan WH: Dynamic regulation of leptin entry into brain by the blood-brain barrier. Regul Pept 92: 37-43, 2000.

26. Witte AV, Kobe T, Graunke A, Schuchardt JP, Hahn A, Tesky VA, Pantel J and Flöel A: Impact of leptin on memory function and hippocampal structure in mild cognitive impairment. Hum Brain Mapp 37: 4539-4549, 2016.

27. Chowen JA, Argente-Arizon P, Freire-Regatillo A, Frago LM, Horvath TL and Argente J: The role of astrocytes in the hypothalamic response and adaptation to metabolic signals. Prog Neurobiol 144: 68-87, 2016.

28. Escobar S, Rocha A, Felip A, Carrillo M, Zanuy S, Kah O and Servili A: Leptin receptor gene in the European sea bass (Dicentrarchus labrax): Cloning, phylogeny, tissue distribution and neuroanatomical organization. Gen Comp Endocrinol 229: 100-111, 2016.

29. Engel O, Kolodziej S, Dirnagl U and Prinz V: Modeling stroke in mice - middle cerebral artery occlusion with the filament model. J Vis Exp 6: 2423, 2011. 
30. Thomas SA, Preston JE, Wilson MR, Farrell CL and Segal MB Leptin transport at the blood-cerebrospinal fluid barrier using the perfused sheep choroid plexus model. Brain Res 895: 283-290, 2001

31. Kwon O, Kim KW and Kim MS: Leptin signalling pathways in hypothalamic neurons. Cell Mol Life Sci 73: 1457-1477, 2016.

32. Deng ZH Jr, Yan GT, Wang LH, Zhang JY, Xue H and Zhang K: Leptin relieves intestinal ischemia/reperfusion injury by promoting ERK1/2 phosphorylation and the NO signaling pathway. J Trauma Acute Care Surg 72: 143-149, 2012.

33. Zhang J, Deng Z, Liao J, Song C, Liang C, Xue H, Wang L, Zhang $\mathrm{K}$ and Yan G: Leptin attenuates cerebral ischemia injury through the promotion of energy metabolism via the PI3K/Akt pathway. J Cereb Blood Flow Metab 33: 567-574, 2013.

34. Zhang F, Wang S, Signore AP and Chen J: Neuroprotective effects of leptin against ischemic injury induced by oxygen-glucose deprivation and transient cerebral ischemia. Stroke 38: 2329-2336, 2007.

35. Amantea D, Tassorelli C, Russo R, Petrelli F, Morrone LA, Bagetta G and Corasaniti MT: Neuroprotection by leptin in a rat model of permanent cerebral ischemia: Effects on STAT3 phosphorylation in discrete cells of the brain. Cell Death Dis 2: e238, 2011.

36. Liu Z, Gan L, Zhou Z, Jin W and Sun C: SOCS3 promotes inflammation and apoptosis via inhibiting JAK2/STAT3 signaling pathway in 3T3-L1 adipocyte. Immunobiology 220 947-953, 2015.

37. Wang W, Lu R, Feng DY and Zhang H: Sevoflurane inhibits glutamate-aspartate transporter and glial fibrillary acidic protein expression in hippocampal astrocytes of neonatal rats through the janus kinase/signal transducer and activator of transcription (JAK/STAT) pathway. Anesth Analg 123: 93-102, 2016.

38. Lin G, Zhang H, Sun F, Lu Z, Reed-Maldonado A, Lee YC, Wang G, Banie L and Lue TF: Brain-derived neurotrophic factor promotes nerve regeneration by activating the JAK/STAT pathway in Schwann cells. Transl Androl Urol 5: $167-175,2016$

39. Lv J, Wang X, Liu SY, Liang PF, Feng M, Zhang LL and Xu AP: Protective effect of Fenofibrate in renal ischemia reperfusion injury: Involved in suppressing kinase 2 (JAK2)/transcription 3 (STAT3)/p53 signaling activation. Pathol Biol (Paris) 63: 236-242, 2015.

40. Garama DJ, White CL, Balic JJ and Gough DJ: Mitochondrial STAT3: Powering up a potent factor. Cytokine 87: 20-25, 2016.

41. Gurzov EN, Stanley WJ, Pappas EG, Thomas HE and Gough DJ: The JAK/STAT pathway in obesity and diabetes. FEBS J 283 3002-3015, 2016.

42. Meng HL, Li XX, Chen YT, Yu LJ, Zhang H, Lao JM, Zhang X and Xu Y: Neuronal soluble fas ligand drives M1-microglia polarization after cerebral ischemia. CNS Neurosci Ther 22 771-781, 2016

43. Friedman J: The long road to leptin. J Clin Invest 126: 4727-4734, 2016.

44. Moon HS, Dalamaga M, Kim SY, Polyzos SA, Hamnvik OP, Magkos F, Paruthi J and Mantzoros CS: Leptin's role in lipodystrophic and nonlipodystrophic insulin-resistant and diabetic individuals. Endocr Rev 34: 377-412, 2013.

45. Pan WW and Myers MG Jr: Leptin and the maintenance of elevated body weight. Nat Rev Neurosci 19: 95-105, 2018.

46. Davis C, Mudd J and Hawkins M: Neuroprotective effects of leptin in the context of obesity and metabolic disorders. Neurobiol Dis 72: 61-71, 2014.

47. Nuñez-Figueredo Y, Pardo-Andreu GL, Ramírez-Sánchez J, Delgado-Hernández R, Ochoa-Rodríguez E, Verdecia-Reyes Y, Naal Z, Muller AP, Portela LV and Souza DO: Antioxidant effects of JM-20 on rat brain mitochondria and synaptosomes: Mitoprotection against $\mathrm{Ca} 2+-$-induced mitochondrial impairment. Brain Res Bull 109: 68-76, 2014.

48. Hana V, Silha JV, Justova V, Lacinova Z, Stepan JJ and Murphy LJ: The effects of GH replacement in adult GH-deficient patients: Changes in body composition without concomitant changes in the adipokines and insulin resistance. Clin Endocrinol (Oxf) 60 442-450, 2004

49. Cundrle I Jr, Somers VK, Singh P, Johnson BD, Scott CG and Olson LJ: The relationship between leptin and ventilatory control in heart failure. J Card Fail 19: 756-761, 2013.

50. Tang H, Zhang Z, Li ZK, Lin J and Fang DZ: Association of leptin receptor gene polymorphisms with genetic susceptibility to ischemic stroke. J Stroke Cerebrovasc Dis 24: 2128-2133, 2015 .
51. Auer MK, Ebert T, Pietzner M, Defreyne J, Fuss J, Stalla GK and T'Sjoen G: Effects of sex hormone treatment on the metabolic syndrome in transgender individuals: Focus on metabolic cytokines. J Clin Endocrinol Metab 103: 790-802, 2018.

52. Saber H, Himali JJ, Shoamanesh A, Beiser A, Pikula A, Harris TB, Roubenoff R, Romero JR, Kase CS, Vasan RS and Seshadri S: Serum leptin levels and the risk of stroke: The framingham study. Stroke 46: 2881-2885, 2015.

53. Diaz M, Chacon MR, Lopez-Bermejo A, Maymó-Masip E, Salvador C, Vendrell J, de Zegher F and Ibáñez L: Ethinyl estradiol-cyproterone acetate versus low-dose pioglitazone-flutamide-metformin for adolescent girls with androgen excess: Divergent effects on CD163, TWEAK receptor, ANGPTL4, and LEPTIN expression in subcutaneous adipose tissue. J Clin Endocrinol Metab 97: 3630-3638, 2012.

54. Scott I, Webster BR, Chan CK, Okonkwo JU, Han K and Sack MN: GCN5-like protein 1 (GCN5L1) controls mitochondrial content through coordinated regulation of mitochondrial biogenesis and mitophagy. J Biol Chem 289: 2864-2872, 2014.

55. Martinez-Abundis E, Rajapurohitam V, Gertler A and Karmazyn M: Identification of functional leptin receptors expressed in ventricular mitochondria. Mol Cell Biochem 408: $155-162,2015$.

56. Karadottir R, Cavelier P, Bergersen LH and Attwell D: NMDA receptors are expressed in oligodendrocytes and activated in ischaemia. Nature 438: 1162-1166, 2005.

57. Hamilton NB, Kolodziejczyk K, Kougioumtzidou E and Attwell D: Proton-gated $\mathrm{Ca}(2+)$-permeable TRP channels damage myelin in conditions mimicking ischaemia. Nature 529: 523-527, 2016.

58. Greco SJ, Hamzelou A, Johnston JM, Smith MA, Ashford JW and Tezapsidis N: Leptin boosts cellular metabolism by activating AMPK and the sirtuins to reduce tau phosphorylation and $\beta$-amyloid in neurons. Biochem Biophys Res Commun 414: 170-174, 2011.

59. Busch HJ, Schirmer SH, Jost M, van Stijn S, Peters SL, Piek JJ, Bode C, Buschmann IR and Mies G: Leptin augments cerebral hemodynamic reserve after three-vessel occlusion: Distinct effects on cerebrovascular tone and proliferation in a nonlethal model of hypoperfused rat brain. J Cereb Blood Flow Metab 31: 1085-1092, 2011.

60. Gleitz HF, Kramann R and Schneider RK: Understanding deregulated cellular and molecular dynamics in the haematopoietic stem cell niche to develop novel therapeutics for bone marrow fibrosis. J Pathol 245: 138-146, 2018.

61. Ray A and Cleary MP: The potential role of leptin in tumor invasion and metastasis. Cytokine Growth Factor Rev 38: 80-97, 2017.

62. Ni H, Sun Q, Tian T, Feng X and Sun BL: Long-term expression of metabolism-associated genes in the rat hippocampus following recurrent neonatal seizures and its regulation by melatonin. Mol Med Rep 12: 2727-2734, 2015.

63. Zhang XG, Zhao L, Zhang Y, Li YY, Wang H, Duan GL Xiao L, Li XR and Chen HP: Extracellular Cl(-)-free-induced cardioprotection against hypoxia/reoxygenation is associated with attenuation of mitochondrial permeability transition pore. Biomed Pharmacother 86: 637-644, 2017.

64. Warne J, Pryce G, Hill JM, Shi X, Lennerås F, Puentes F, Kip M, Hilditch L, Walker P, Simone MI, et al: Selective inhibition of the mitochondrial permeability transition pore protects against neurodegeneration in experimental multiple sclerosis. J Biol Chem 291: 4356-4373, 2016.

65. Ham PB 3rd and Raju R: Mitochondrial function in hypoxic ischemic injury and influence of aging. Prog Neurobiol 157: 92-116, 2017

66. Holmstrom MH, Tom RZ, Bjornholm M, Garcia-Roves PM and Zierath JR: Effect of leptin treatment on mitochondrial function in obese leptin-deficient ob/ob mice. Metabolism 62: 1258-1267, 2013.

67. Hayakawa K, Esposito E, Wang X, Terasaki Y, Liu Y, Xing C, Ji X and Lo EH: Transfer of mitochondria from astrocytes to neurons after stroke. Nature 535: 551-555, 2016.

68. Antico Arciuch VG, Elguero ME, Poderoso JJ and Carreras MC Mitochondrial regulation of cell cycle and proliferation. Antioxid Redox Signal 16: 1150-1180, 2012.

69. Valerio A, Bertolotti P, Delbarba A, Perego C, Dossena M, Ragni M, Spano P, Carruba MO, De Simoni MG and Nisoli E: Glycogen synthase kinase-3 inhibition reduces ischemic cerebral damage, restores impaired mitochondrial biogenesis and prevents ROS production. J Neurochem 116: 1148-1159, 2011. 
70. Madathil RJ, Hira RS, Stoeckl M, Sterz F, Elrod JB and Nichol G: Ischemia reperfusion injury as a modifiable therapeutic target for cardioprotection or neuroprotection in patients undergoing cardiopulmonary resuscitation. Resuscitation 105: 85-91, 2016.

71. Vermeij JD, Westendorp WF, Dippel DW, van de Beek D and Nederkoorn PJ: Antibiotic therapy for preventing infections in people with acute stroke. Cochrane Database Syst Rev 1: CD008530, 2018.

72. Chung HK, Kim YK, Park JH, Ryu MJ, Chang JY, Hwang JH, Lee CH, Kim SH, Kim HJ, Kweon GR, et al: The indole derivative NecroX-7 improves nonalcoholic steatohepatitis in ob/ob mice through suppression of mitochondrial ROS/RNS and inflammation. Liver Int 35: 1341-1353, 2015.

73. Rustenhoven J, Aalderink M, Scotter EL, Oldfield RL, Bergin PS, Mee EW, Graham ES, Faull RL, Curtis MA, Park TI and Dragunow M: TGF-betal regulates human brain pericyte inflammatory processes involved in neurovasculature function. J Neuroinflammation 13: 37, 2016.

74. Agrawal S, Gollapudi S, Su H and Gupta S: Leptin activates human B cells to secrete TNF- $\alpha$, IL-6, and IL-10 via JAK2/STAT3 and p38MAPK/ERK1/2 signaling pathway. J Clin Immunol 31: 472-478, 2011.

75. Xu H, Qin W, Hu X, Mu S, Zhu J, Lu W and Luo Y: Lentivirus-mediated overexpression of OTULIN ameliorates microglia activation and neuroinflammation by depressing the activation of the NF- $\mathrm{KB}$ signaling pathway in cerebral ischemia/reperfusion rats. J Neuroinflammation 15: 83, 2018.

76. Rummel C: Inflammatory transcription factors as activation markers and functional readouts in immune-to-brain communication. Brain Behav Immun 54: 1-14, 2016.

77. Lopez-Rodriguez AB, Mela V, Acaz-Fonseca E, Garcia-Segura LM and Viveros MP: CB2 cannabinoid receptor is involved in the anti-inflammatory effects of leptin in a model of traumatic brain injury. Exp Neurol 279: 274-282, 2016.

78. Flatow EA, Komegae EN, Fonseca MT, Brito CF, Musteata FM, Antunes-Rodrigues $\mathrm{J}$ and Steiner AA: Elucidating the role of leptin in systemic inflammation: A study targeting physiological leptin levels in rats and their macrophages. Am J Physiol Regul Integr Comp Physiol 313: R572-R582, 2017.

79. Astrup J, Symon L and Siesjo BK: Thresholds in cerebral ischemia-the ischemic penumbra. Stroke 12: 723-725, 1981.

80. Stetler RA, Leak RK, Yin W, Zhang L, Wang S, Gao Y and Chen J: Mitochondrial biogenesis contributes to ischemic neuroprotection afforded by LPS pre-conditioning. J Neurochem 123 (Suppl 2): 125-137, 2012.
81. Tan DX, Manchester LC, Qin L and Reiter RJ: Melatonin: A mitochondrial targeting molecule involving mitochondrial protection and dynamics. Int J Mol Sci 17: E2124, 2016.

82. Geng HX, Li RP, Li YG, Wang XQ, Zhang L, Deng JB, Wang L and Deng JX: 14,15-EET suppresses neuronal apoptosis in ischemia-reperfusion through the mitochondrial pathway. Neurochem Res 42: 2841-2849, 2017.

83. Owens B: Stroke. Nature 26: 510(7506):S1, 2014

84. Grummisch JA, Jadavji NM and Smith PD: tPA promotes cortical neuron survival via mTOR-dependent mechanisms. Mol Cell Neurosci 74: 25-33, 2016.

85. Arita S, Kinoshita Y, Ushida K, Enomoto A and Inagaki-Ohara K: High-fat diet feeding promotes stemness and precancerous changes in murine gastric mucosa mediated by leptin receptor signaling pathway. Arch Biochem Biophys 610: 16-24, 2016.

86. Carboni L, Marchetti L, Lauria M, Gass P, Vollmayr B, Redfern A, Jones L, Razzoli M, Malki K, Begni V, et al: Cross-species evidence from human and rat brain transcriptome for growth factor signaling pathway dysregulation in major depression. Neuropsychopharmacology 43: 234-2145, 2018.

87. Yang H, Guo W, Li J, Cao S, Zhang J, Pan J, Wang Z, Wen P, Shi X and Zhang S: Leptin concentration and risk of coronary heart disease and stroke: A systematic review and meta-analysis. PLoS One 12: e0166360, 2017.

88. Brüstle O, Choudhary K, Karram K, Hüttner A, Murray K, Dubois-Dalcq M and McKay RD: Chimeric brains generated by intraventricular transplantation of fetal human brain cells into embryonic rats. Nat Biotechnol 16: 1040-1044,1998

89. Nakatomi H, Kuriu T, Okabe S, Yamamoto S, Hatano O, Kawahara N, Tamura A, Kirino T and Nakafuku M: Regeneration of hippocampal pyramidal neurons after ischemic brain injury by recruitment of endogenous neural progenitors. Cell 110 : 429-441, 2002

90. Carlen M, Meletis K, Goritz C, Darsalia V,Evergren E, Tanigaki K, Amendola M, Barnabé-Heider F, Yeung MS, Naldini L, et al: Forebrain ependymal cells are Notch-dependent and generate neuroblasts and astrocytes after stroke. Nat Neurosc 12: 259-267, 2009.

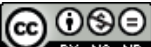

This work is licensed under a Creative Commons

Attribution-NonCommercial-NoDerivatives 4.0 International (CC BY-NC-ND 4.0) License. 